\title{
BIOMINERALIZATION OF MAGNETIC IRON MINERALS IN BACTERIA
}

by

\author{
Richard B. Frankel ${ }^{\mathrm{a}}$, Dennis A. Bazylinski ${ }^{\mathrm{b}}$, and Dirk Schüler ${ }^{\mathrm{b}}$
}

a Department of Physics, California Polytechnic State University, San Luis Obispo, CA 93407, USA

${ }^{b}$ Department of Microbiology, Immunology, and Preventive Medicine, Iowa State University, Ames, IA 50011, USA

\begin{abstract}
Magnetotactic bacteria orient and migrate along magnetic field lines. This ability is based on a submicron assembly of single-magnetic domain iron mineral particles that elegantly solves the problem of how to construct a magnetic dipole that is large enough be oriented in the geomagnetic field at ambient temperature, yet fit inside a micron-sized cell. The solution is based on the ability of the bacteria to accumulate high concentrations of iron, and control the deposition, size and orientation of a specific iron mineral at specific locations in the cell.
\end{abstract}

\section{INTRODUCTION}

Many organisms mediate the deposition of minerals. In biologically-controlled mineralization, minerals are deposited in a specific location, either on an organic interface or within a vesicle, from supersaturated solutions that are generated by biochemical processes ${ }^{1}$. Thus biologically-controlled mineralization is ultimately connected to cellular metabolic and genetic control. Nucleation and growth of the mineral phase can be activated chemically or interfacially, and the role of the organic matrices is of paramount importance in controlling the mineralization process. An example of biologically-controlled mineralization is afforded by magnetic iron mineral particle formation in magnetotactic bacteria. The mineral particles are generally characterized as being well-ordered crystals of a specific mineral type, having narrow size distributions and very specific particle morphologies. The are arranged within the cell to produce a permanent magnetic dipole that is a masterpiece of permanent magnet engineering.

\section{MAGNETOTATIC BACTERIA}

Magnetotactic bacteria orient and migrate along geomagnetic field lines ${ }^{2,3}$. Each cell contains magnetosomes, which are membrane-enclosed, iron-mineral particles ${ }^{4-6}$. The magnetosomes are typically aligned in a chain, with the chain orientation close to the axis of motility of the cell ${ }^{7,8}$. In magnetotactic bacteria from microaerobic freshwater and marine 
environments the magnetosome iron mineral is magnetite, $\mathrm{Fe}_{3} \mathrm{O}_{4}{ }^{9}$ whereas greigite, $\mathrm{Fe}_{3} \mathrm{~S}_{4}$, is found in magnetotactic bacteria from sulfidic environments ${ }^{10-12}$. The magnetosome membrane is presumably a structural entity that anchors the mineral particles at particular locations in the cell, as well as the locus of biological control over the mineralization process.

The magnetotactic bacteria represent a heterogeous group of procaryotes with a myriad of cellular morphologies including coccoid (spherical or more or less so), rod-shaped, vibrioid (curved), spirilloid (helical) and even multicellular ${ }^{6,13}$. All that have been examined to date are Gram-negative members of the Domain Bacteria although this does not exclude the possibility of a magnetotactic member of the Archaea. Thus, the term "magnetotactic bacteria" has no taxonomic significance and should be interpreted as a term for a collection of diverse bacteria that possess the apparently widely distributed trait of magnetotaxis ${ }^{6}$.

Despite the great diversity of the magnetotactic bacteria, they all share several features: (1) they are all motile; (2) all exhibit a negative tactile and/or growth response to atmospheric concentrations of oxygen; and (3) they all possess magnetosomes.

\section{PROPERTIES OF MAGNETOSOME PARTICLES}

An electron micrograph of magnetite particles in the magnetotactic bacterium Magnetospirillum magnetotacticum is shown in Figure 1. The particle morphology of the particles is cubo-octahedral, with [111] axes oriented along the direction of the chain ${ }^{14}$. A narrow particle-size distribution and consistent, species-specific particle morphology and orientation are characteristic of the magnetite biomineralization processes in all magnetotactic bacteria ${ }^{7}$. Three general morphologies of magnetite particles have been observed in magnetotactic bacteria using transmission electron microscopy (TEM). They include: (1) roughly cuboidal ${ }^{4}$; (2) parallelepipedal (rectangular in the horizontal plane of projection) ${ }^{15,16}$; and (3) tooth-, bullet- or arrowhead-shaped (anisotropic) ${ }^{17-20}$. Examples are shown in Figure 2.

High resolution analytical TEM studies have revealed that the magnetite particles within magnetotactic bacteria are of high structural perfection and have been used to determine their idealized morphologies ${ }^{10,14,17,18,21-24}$. These studies have shown the roughly cuboidal particles to be truncated cubo-octahedra and the parallelepipedal particles to be either truncated hexahedral or octahedral prisms. The cubo-octahedral crystal morphology preserves the symmetry of the face-centered cubic spinel structure and is considered an equilibrium growth form of magnetite which simply means that this morphology can be expected to be found in chemically-produced magnetite particles. The hexa- and octahedral prismatic particles represent departures from this equilibrium form, presumably due to the acceleration or deceleration of mineral growth of certain crystal faces ${ }^{25,26}$. 
The synthesis of the tooth-, bullet- and arrowhead-shaped magnetite particles appears to be more complex than that of the other forms. They have been examined by high resolution TEM in one uncultured organism ${ }^{17,18}$. The idealized morphology of these particles suggests that their growth occurs in two stages. The first, during which the length and width develop concurrently, is the formation of a well-ordered, cubo-octahedral crystal. The second stage involves anisotropic growth of the crystal along a preferred direction.

Whereas the cubo-octahedral form of magnetite is common in inorganically-formed magnetites, the prevalence of elongated hexahedral or octahedral forms in magnetosome crystals appears to be a unique feature of the BCM process ${ }^{26}$. This aspect of magnetosome particle morphology forms the basis for distinguishing magnetosome magnetite from detrital magnetite, or magnetite resulting from uncontrolled mineralization of metalbolic waste products such as $\mathrm{Fe}(\mathrm{II})^{27}$.

The iron sulfide magnetosomes contain either particles of greigite ${ }^{28,29}$ or a mixture of greigite and pyrite ${ }^{10}$. Only two morphologies of greigite have been observed in magnetotactic bacteria: (1) cubo-octahedral (the equilibrium form of face-centered cubic greigite); and (2) rectangular prismatic. Like that of magnetite particles, the morphology of the greigite particles also appears to be species- and/or strain-specific although confirmation of this observation will require controlled studies of pure cultures of greigite-producing magnetotactic bacteria, none of which is currently available.

\section{CELLULAR MAGNETIC DIPOLE}

Although variations exist between species, almost all magnetosomes, regardless of whether they contain magnetite or greigite, fall within the narrow size range of about 35-120 $\mathrm{nm}$ when measured along their long axes ${ }^{7,20,28-31}$. This size range is significant because it places these particles within the stable magnetic single domain (SD) size range for magnetite and greigite ${ }^{32}$. Particles within the SD size range are uniformly magnetized and their remanent magnetic moment is a maximum, equal to the saturation moment. Particles larger than about 100 to $120 \mathrm{~nm}$ are non-uniformly magnetized because of the formation of multiple magnetic domains, domain walls, or vortex configurations; this has the effect of making their magnetic moments significantly smaller than in SD particles. At the other extreme, SD particles smaller than about $30 \mathrm{~nm}$ are superparamagnetic (SPM). Although SPM particles are still uniformly magnetized, their moments are not constant in direction because of thermally-induced spontaneous reversals which produce a time-averaged moment of zero. Therefore, magnetotactic bacteria produce the optimum particle size for maximum moment per magnetosome.

The crystallographic orientation of each individual magnetosome along a chain is also significant. Magnetite magnetosomes are almost exclusively oriented with their [111] crystallographic axes aligned along the chain axis, as determined by high resolution electron 
microscopy ${ }^{25}$. Even for elongated crystal morphologies, one of the four [111] directions is usually the axis of elongation. In contrast, greigite magnetosomes are oriented such that the [100] direction is parallel to the chain axis ${ }^{29}$. The significance of the [111] direction in magnetite is that it corresponds to the magnetic easy axis. Similarly, the [100] direction is probably the magnetic easy axis in greigite. No direct determination of easy axis orientation in greigite has been made, primarily because of the difficulty of synthesizing high quality, large single crystals of this mineral usually required for magnetic anisotropy measurements.

When magnetosomes are arranged in a single chain, as in M. magnetotacticum, magnetostatic interactions between the single-magnetic domain particles cause the particle moments to spontaneously orient parallel to each other along the chain direction ${ }^{3,33}$. This results in a permanent magnetic dipole for the chain of magnetosomes with natural remanent magnetization approaching the saturation magnetization. A cell with a chain of twenty 50 $\mathrm{nm}^{3}$ magnetosomes would have a magnetic dipole moment of ca. 1E-12 emu, sufficient for orientation of the moment along the geomagnetic field at ambient temperature. Since the chain of particles is fixed within the cell, the entire cell is oriented by the torque exerted on the magnetic dipole by the magnetic field. This results in the migration of the cell along the magnetic field as it swims.

The permanent magnetic dipole nature of the magnetosome chain has been demonstrated by pulsed magnetic field remanence measurements on individual cells of $M$. magnetotacticum ${ }^{34}$. In these measurements, cells aligned in a weak (ca. $10 \mathrm{G}$ ) field were subjected to short, magnetic-field pulses of increasing amplitude, oriented opposite to the weak alignment field. Following each pulse, the relative magnetic moment of the cell was determined using a rotating magnetic field method. The results showed that the hysteresis loops of M. magnetotacticum cells were square, with a coercive force of about $300 \mathrm{G}$, with variation in the coercive force from cell to cell attributable to differences in length of the magnetosome chain. These results are consistent with bulk measurements on whole cells ${ }^{34,35}$.

\section{ECOLOGY OF MAGNETOTACTIC BACTERIA}

Magnetotactic bacteria are ubiquitous in aquatic habitats and are cosmopolitan in distribution ${ }^{13}$. They are generally found in the highest numbers at the oxic-anoxic transition zone (OATZ) also referred to as the microaerobic zone or the redoxocline. In many freshwater habitats, the OATZ is located at the sediment-water interface or just below it. However, in some brackish-to-marine systems, the OATZ is found or is seasonally located in the water column.

The Pettaquamscutt Estuary (Narragansett Bay, RI, USA) ${ }^{36}$ and Salt Pond (Woods Hole, MA, USA) ${ }^{37}$ are good examples of the latter situation. Hydrogen sulfide, produced by sulfate-reducing bacteria in the anaerobic zone and sediment, diffuses upward while oxygen diffuses downward from the surface resulting in a double, vertical chemical concentration 
gradient with a co-existing redox gradient. In addition, strong pycnoclines and other physical factors, including the microorganisms themselves, stabilize the vertical chemical gradients and the resulting OATZ.

Many types of magnetotactic bacteria are found at both the Pettaquamscutt Estuary ${ }^{38}$ and Salt Pond. Generally, the magnetite-producing magnetotactic bacteria prefer the OATZ proper and behave as microaerophiles. Cultural information supports this observation. Two strains of magnetotactic bacteria have been isolated from the Pettaquascutt. One is a vibrio designated strain MV-2 ${ }^{24,39}$ and the other is a coccus designated strain MC-1 ${ }^{23,39,40}$. Both strains grow as microaerophiles although strain MV-2 can also grow anaerobically with nitrous oxide $\left(\mathrm{N}_{2} \mathrm{O}\right)$ as a terminal electron acceptor. A similar, possibly identical, organism, designated strain MV-1 was isolated previously from another marine site ${ }^{16}$. Cells of this species are very versatile nutritionally being able to grow chemoorganoheterotrophically with organic acids as carbon and energy sources and chemolithoautotrophically with thiosulfate or sulfide as energy sources and carbon dioxide as the sole carbon source ${ }^{41}$. Cells use the Calvin-Benson cycle for autotrophic carbon dioxide fixation, as cell-free extracts from thiosulfate-grown cells show ribulose bisphosphate carboxylase/oxygenase activity ${ }^{41}$. Other cultured magnetotactic bacterial strains, including spirilla ${ }^{42-44}$ and rods ${ }^{45}$, are microaerophiles or anaerobes or both.

The greigite-producing bacteria appear to prefer the more sulfidic waters just below the OATZ where the oxygen concentration is zero and are likely anaerobes ${ }^{6,38}$. To date, no greigite-producing magnetotactic bacterium has been isolated and grown in pure culture.

\section{CHEMISTRY AND BIOCHEMISTRY OF MAGNETOSOME FORMATION}

In all the magnetite-producing magnetotactic bacteria examined to date, the magnetosome mineral phase appears to be enveloped by a membrane. In cells of $M$. magnetotacticum, the magnetosome membrane was found to consist of a lipid bilayer containing phospholipids and numerous proteins, some of which appear to be unique to this membrane and not the outer or cytoplasmic membrane ${ }^{5}$. The magnetosome membrane does not appear to be contiguous with the cell membrane. Also, it is not known if the magnetosome membrane is premade as an "empty" membrane vesicle prior to the biomineralization of the mineral phase. Empty and partially filled vesicles have been observed in iron-starved cells of $M$. magnetotacticum ${ }^{5}$, and similar structures have also been observed in M. gryphiswaldense (D. Schüler and E. Baeuerlein, unpublished results). An unlikely alternative would be that nucleation of the mineral phase occurs prior to its being surrounded by membrane. In any case, most biochemical and molecular biological studies directed towards the understanding of the biomineralization processes involved in magnetosome formation are focused on aspects of the magnetosome membrane, particularly on the functions of specific proteins present on this membrane. 
The first step in magnetite synthesis in magnetotactic bacteria is the uptake of iron. Free reduced $\mathrm{Fe}\left(\mathrm{II}\right.$ ) is very soluble (up to $100 \mathrm{mM}$ at neutral $\mathrm{pH}^{46}$ ) and is easily taken up by bacteria, usually by non-specific means. However, because free oxidized Fe(III) is so insoluble, most microbes have to rely on iron chelators which bind and solubilize Fe(III) for uptake under aerobic conditions. Microbially produced Fe(III) chelators, called siderophores, are low molecular weight $(<1 \mathrm{kDa})$, virtually specific ligands that facilitate the solubilization and transport of $\mathrm{Fe}(\mathrm{III}){ }^{47}$. Siderophores are generally only produced under iron-limited conditions and their synthesis repressed under high iron conditions.

Several studies, all involving magnetotactic spirilla, have focused on iron uptake in the magnetotactic bacteria. Paoletti and Blakemore reported the production of a hydroxamate siderophore by cells of $M$. magnetotacticum grown under high but not under low iron conditions ${ }^{48}$, i.e., the reverse of what is normally observed. However, these results have not been replicated. Earlier, Frankel et al. assumed that iron uptake by this organism probably occurred via a non-specific transport system ${ }^{49}$. Although iron is supplied as Fe(III) chelated to quinic acid, the growth medium also contains chemical reducing agents (e.g. thioglycollate or ascorbic acid) potent enough to reduce Fe(III) to Fe(II). Thus, both forms of iron are present in the growth medium and it is not known which form is taken up by the cells.

Nakamura et al. could not detect siderophore production by Magnetospirillum AMB1 and concluded that iron was taken up as $\mathrm{Fe}$ (III), with uptake mediated by a periplasmic binding protein-dependent iron transport system ${ }^{5}$. Schüler and Baeuerlein found that spent medium stimulated iron uptake to a high degree in cells of M. gryphiswaldense but found no evidence for the presence of a siderophore ${ }^{51}$. They also showed that the major portion of iron for magnetite synthesis was taken up as $\mathrm{Fe}$ (III) at high rates in an energy-dependent process. Both the amount of magnetite formed, and the rate of ferric iron uptake in this organism, were close to saturation at extracellular iron concentrations of $15-20 \mathrm{mM} \mathrm{Fe}(\mathrm{III})$, indicating that this bacterium is able to take up and accumulate copious amounts of iron from relatively low environmental concentrations. The uptake of iron during the growth in $M$. gryphiswaldense was tightly coupled to the induction of magnetite biomineralization. Irondepleted cells of this species had a higher potential for iron accumulation and magnetite formation during microaerobic growth compared to iron-adapted cells ${ }^{52}$.

In an effort to understand the relationship between nitrate and oxygen utilization and magnetite synthesis, electron transport and cytochromes in M. magnetotacticum have been examined. Tamegai et al. reported a novel "cytochrome a1-like" hemoprotein that was in greater amounts in magnetic cells than nonmagnetic cells ${ }^{53}$. They did not find any true cytochrome a1 that was once considered to be one of the terminal oxidases, as well as an otype cytochrome, in M. magnetotacticum ${ }^{54}$. A new ccb-type cytochrome c oxidase ${ }^{55}$ and a cytochrome cd 1 -type nitrite reductase ${ }^{56}$ were isolated and purified from $M$.

magnetotacticum. The latter protein was of particular interest since it showed Fe(II):nitrite 
oxido-reductase activity which may be linked to the oxidation of $\mathrm{Fe}(\mathrm{II})$ in the cell and thus to magnetite synthesis ${ }^{56}$.

Only one study has addressed what occurs after iron is taken up by magnetotactic bacteria. Frankel et al. examined the nature and distribution of major iron compounds in $M$. magnetotacticum by using Fe-57 Moessbauer spectroscopy ${ }^{49}$. They proposed a model in which Fe(III) is taken up by the cell and reduced to Fe(II) as it enters the cell. It is then thought to be reoxidized to form a low-density hydrous Fe(III) oxide which is then dehydrated to form a high-density Fe(III) oxide (ferrihydrite) which was directly observed in cells. In the last step, one-third of the Fe(III) ions in ferrihydrite are reduced, and with further dehydration, magnetite is produced. How specific shapes of magnetite are formed is unknown at present but it is thought that the final two steps occur in the magnetosome membrane vesicle which acts as a further constraint on crystal growth.

\section{MOLECULAR BIOLOGY OF MAGNETOTACTIC BACTERIA}

Little is known about the molecular biology of magnetosome formation, i.e., how many genes are required for magnetosome synthesis, how the genes are regulated, etc. Several laboratories are trying to establish a genetic system with the magnetotactic bacteria but they have been hampered by many problems including, for example, the lack of a significant number of magnetotactic bacterial strains, the fastidiousness of the organisms in culture and the elaborate techniques required for the growth of these organisms and the inability for almost all these strains to grow on the surface of agar plates to screen for mutants etc. While different approaches have been taken, most of the genetic and molecular studies have involved one or more of the magnetotactic spirilla.

The first studies in the establishment of a genetic system with magnetotactic bacteria. were made with Magnetospirillum magnetotacticum strain MS-1 ${ }^{57,58}$. It was shown that at least some of the genes of this organism can be functionally expressed in Escherichia coli and that the transcriptional and translational elements of the two microorganisms are compatible. Berson et al. were able to clone, characterize and sequence the recA gene from M. magnetotacticum ${ }^{58,59}$. They then cloned and characterized a $2 \mathrm{~kb}$ DNA fragment from $M$. magnetotacticum that complemented the $\operatorname{aroD}$ (biosynthetic dehydoquinase) gene function in E. coli and Salmonella typhimurium. AroD mutants of these strains cannot take up iron from the growth medium, but when the $2 \mathrm{~kb}$ DNA fragment from $M$. magnetotacticum was introduced into these mutants, the ability of the mutants to take up iron from the growth medium was restored ${ }^{60}$ suggesting that the $2 \mathrm{~kb}$ DNA fragment is important in iron uptake (and therefore possibly in magnetite synthesis) in M. magnetotacticum.

Matsunaga et al. isolated a magnetotactic spirillum, designated Magnetospirillum strain AMB-1, that is apparently much more oxygen tolerant than other magnetotactic species and can form colonies on the surface of agar plates under fully aerobic conditions $\left(21 \% \mathrm{O}_{2}\right)$ 
${ }^{44}$. Cells grown this way formed white colonies that contained non-magnetic cells. However, when the oxygen concentration of the incubation atmosphere was reduced to $2 \%$, blackbrown colonies formed that contained magnetic cells. This feature facilitated the selection of non-magnetic mutants of Magnetospirillum strain AMB-1 obtained by the introduction of transposon Tn5 into the genome of Magnetospirillum AMB-1 by the conjugal transfer of plasmid pSUP1021 which contained the transposon ${ }^{61}$. This plasmid and transposon were also introduced into M. magnetotacticum, but colony formation in this strain was not achieved. It was concluded that at least three regions of the Magnetospirillum strain AMB-1 chromosome are required for the successful synthesis of magnetosomes. One of these regions was found to contain a gene, designated $\operatorname{mag}^{62}{ }^{62}$, that encodes for a protein that is homologous to the cation efflux proteins, the Escherichia coli potassium ion-translocating protein, KefC, and the putative sodium ion/proton antiporter, NapA, from Enterococcus hirae. MagA was expressed in E. coli and membrane vesicles prepared from these cells that contained the magA gene product took up iron when ATP was supplied indicating that energy was required for the uptake of iron. Nakamura et al. reported that the $m a g A$ gene was expressed to a much greater degree when wild-type Magnetospirillum AMB-1 cells were grown uder iron-limited conditions rather than iron-sufficient conditions in which they would produce more magnetosomes. Also, the nonmagnetotactic Tn5 mutant over-expressed the $m a g A$ gene under iron-limited conditions although it did not make magnetosomes ${ }^{62}$. Thus, the role of the magA gene in magnetosome synthesis is unclear.

Okuda et al. took a different "reverse genetics" approach to the magnetosome problem ${ }^{63}$. They found three proteins with apparent molecular weights of 12, 22 and $28 \mathrm{kDa}$ that appeared to be unique to the magnetosome membranes of Magnetospirillum magnetotacticum and are not present in the cellular membrane fraction. They were able to get enough $\mathrm{N}$-terminal amino acid sequence of the $22 \mathrm{kDa}$ protein and use the genetic code to make a $17 \mathrm{bp}$ oligonucleotide probe for the genomic cloning of the gene encoding for that protein. They also found that the protein exhibited significant homology with a number of proteins that belong to the tetratricopeptide repeat protein family which include mitochondrial protein import receptors and peroxisomal protein import receptors. Thus, although the role of the $22 \mathrm{kDa}$ magnetosome membrane protein in magnetosome synthesis has not been elucidated, it may function as a receptor interacting with associated cytoplasmic proteins ${ }^{63}$.

An organism has been found to contain arrowhead-shaped crystals of magnetite and rectangular prismatic crystals of greigite co-organized within the same chains of magnetosomes (this organism usually contains two parallel chains of magnetosomes) ${ }^{38,64}$. The magnetite and greigite crystals were biomineralized with different, specific morphologies and sizes and were positioned with their long axes oriented along the chain direction. Both particle morphologies had been previously found in other organisms with 
single component chains ${ }^{17,18,28,29}$. This finding suggests that the magnetosome membranes surrounding the magnetite and greigite particles contain different nucleation templates and that there are differences in magnetosome vesicle biosynthesis. Thus, it is likely that two separate sets of genes control the biomineralization of magnetite and greigite in this organism, with a third set controlling chain ultrastructure ${ }^{38}$.

\section{FUNCTION OF MAGNETOTAXIS}

Like most other free swimming bacteria, magnetotactic bacteria propel themselves through the water by rotating their helical flagella ${ }^{65}$. Because of their magnetosomes, magnetotactic bacteria are oriented and migrate along the local magnetic field $\mathbf{B}$. Some magnetotactic spirilla, such as Magnetospirillum magnetotacticum, swim parallel or antiparallel to $\mathbf{B}$ and form aerotactic bands ${ }^{66}$ at a preferred oxygen concentration. In a homogeneous medium, roughly equal numbers of cells swim in either direction along $\mathbf{B}^{66,67}$. This behavior has been termed axial magneto-aerotaxis ${ }^{40}$, because the cells migrate colinear with the magnetic field, with aerotaxis determining the direction of migration along the field. Most microaerophilic bacteria form aerotactic bands at a preferred or optimal oxygen concentration $\left(\left[\mathrm{O}_{2}\right]\right)$, where the proton motive force is maximal ${ }^{68}$, using a temporal sensory

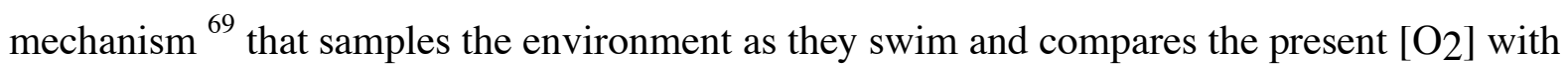
the $\left[\mathrm{O}_{2}\right]$ in the recent past ${ }^{70}$. The change in $\left[\mathrm{O}_{2}\right]$ with time determines the sense of flagellar rotation ${ }^{71}$. The behavior of individual cells of $M$. magnetotacticum in the aerotactic bands in thin capillaries is consistent with the temporal sensory mechanism ${ }^{40}$. Thus cells in the band which are moving away from the optimal oxygen concentration, to either higher or lower oxygen concentration, reverse their swimming direction and return to the band.

In contrast, freshwater and marine, bilophotrichously-flagellated (having two flagellar bundles on one hemisphere of the cell), magnetotactic cocci and some other magnetotactic strains swim persistently in a preferred direction relative to $\mathbf{B}$ when examined microscopically ${ }^{2,33}$. In fact, this persistent swimming of cocci in a preferred direction led to the discovery of magnetotaxis in bacteria ${ }^{2,13}$. The preferred motility direction in the nothern hemisphere is parallel to $\mathbf{B}$ (i.e., North-seeking in the geomagnetic field); in the southern hemisphere it is antiparallel to B (i.e., South-seeking in the geomagnetic field) ${ }^{72}$. Because of the inclination of the geomagnetic field, migration in these preferred directions would cause cells in both hemispheres to migrate downward. Thus the function of magnetotaxis in the magnetoactic cocci has been thought to be facilitation of downward-directed migration for motile bacteria in the water column, towards the microaerobic or anaerobic sediments, and away from higher oxygen concentrations $\left(\left[\mathrm{O}_{2}\right]\right)$ at the water surface ${ }^{2,72}$.

However, it has recently been shown that magnetotactic cocci in oxygen gradients can swim in both directions along $\mathbf{B}$ without turning around ${ }^{40}$. Like cells of M. magnetotacticum, the cocci form microaerophilic, aerotactic bands, that is, they seek a preferred oxygen 
concentration along the concentration gradient. However, while the aerotactic behavior of $M$. magnetotacticum is consistent with the temporal sensory mechanism, the aerotactic behavior of the cocci is not. Instead, their behavior is consistent with a two-state aerotactic sensory model in which the oxygen concentration determines the sense of flagellar rotation and hence swimming direction relative to $\mathbf{B}$. This model, termed polar magneto-aerotaxis, accounts for the ability of magnetotactic cocci to migrate to, and maintain position at, the preferred oxygen concentration at the OATZ in chemically-stratified, semi-anaerobic basins ${ }^{40}$.

We have devised a simple capillary assay that distinguishes between axial magnetoaerotaxis and polar magneto-aerotaxis (Figure 3). In this assay, cells of a given strain are suspended in fresh media or buffer, and are drawn up into a flat, rectangular capillary. The capillary with the cell suspension is left open at both ends, and is placed in the magnetic field with the long axis of the capillary along the magnetic field. Because both ends of the capillary are open, diffusion of air into the capillary will create an oxygen concentration profile in which the concentration is a minimum at the center of the capillary and increases toward both ends.

For M. magnetotacticum and other bacteria that are axial magneto-aerotactic, aerotactic bands formed behind the meniscus at both ends of the capillary. When the magnetic field was subsequently reversed, cells in the bands at both ends rotated 180 degrees, but the bands remained intact. These results were due to the fact that the temporal sensory mechanism is invariant with respect to the relative orientation of the magnetic field and the oxygen concentration gradient.

For cocci, like strain MC-1, and other bacteria that are polar magneto-aerotactic, an aerotactic band formed behind the meniscus only at the one end of the capillary for which the oxygen concentration gradient was oriented antiparallel to the magnetic field. No band formed at the other end. When the magnetic field was subsequently reversed, cells in the aerotactic band rotated 180 degrees, and swam away from the band, i.e., the band ed to disperse. These results were due to the fact that the two-state sensory mechanism depends on the relative orientation of the magnetic field and the oxygen concentration gradient, and the correct orientation occurs at only one end of the capillary.

For both aerotactic mechanisms, migration along the magnetic field reduces a threedimensional search problem to a one-dimensional search problem. Thus magneto-aerotaxis is presumably advantageous to microorganisms in vertical concentration gradients because it increases the efficiency of finding and maintaining a position at the optimal oxygen concentration. It is likely that there are other forms of magnetically-assisted chemotaxis to molecules or ions other than oxygen, such as sulfide, or magnetically-assisted redox- or phototaxis in bacteria that inhabit the anaerobic zone (e.g. greigite-producing bacteria) in chemically-stratified waters and sediments. 


\section{MAGNETOSOMES AND MARS}

Recently, McKay et al. ${ }^{73}$ noted a number of mineralogical and other features from a meteorite of Martian origin designated ALH84001, that was collected in Antarctica. The authors proposed that these features could be explained by biological processes and therefore could represent evidence for ancient life on Mars. Included in these features was the presence of ultrafine-grained magnetite, pyrrhotite and probably greigite. The magnetite crystals ranged from about 10 to $100 \mathrm{~nm}$, i.e., were in the superparamagnetic and single-magnetic domain size ranges, and were cuboid, teardrop and irregular in shape. The iron sulfide particles varied in size and shape, the pyrrhotite particles ranging up to $100 \mathrm{~nm}$. The particles of both mineral were embedded in a fine-grained carbonate matrix on the rim of carbonate inclusions within the meteorite ${ }^{73}$.

The magnetite particles, in particular, were cited as evidence of life because of the similarities in size distribution and morphology between these particles and those produced by magnetotactic bacteria on Earth. In addition, magnetite particles in ALH84001 are very different from those found in other meteorites. Other nanocrystalline forms of magnetite, including platelets and whiskers, are also present in ALH84001. Some of these contain specific crystalline defects (e.g. axial screw dislocations) indicating that they were formed at high temperature, non-biologically, by vapor phase growth ${ }^{74}$. These results show the importance of being able to distinguish between biogenic and non-biogenic forms of iron minerals. Although discussion and debate on the interpretation of these fascinating findings is far from over, it is intriguing to think that microbes may be or have been responsible for $\mathrm{BCM}$ of submicron magnetic iron minerals on other planets in addition to Earth.

\section{ACKNOWLEDGEMENTS}

We are grateful to E. Baeuerlein, P. Busick, D. Dean, B. Howes, M. Johnson, S. Mann, B. Moskowitz, D. Schlezinger, and B. Taylor for discussions and collaboration. This work was supported by US National Science Foundation grant CHE-9714101 and US Office of Naval Research grant ONR N00014-91-J-1290.

\section{REFERENCES}

1. Lowenstam, H. A., Science, 1981, 211, 1126.

2. Blakemore, R.P., Science, 1975, 190, 377.

3. Frankel, R.B. and Blakemore, R.P., J. Magn. Magn. Mater., 1980, 15-18, 1562.

4. Balkwill, D.L., Maratea, D. and Blakemore, R.P., J. Bacteriol., 1980, 141, 1399.

5. Gorby, Y.A., Beveridge, T.J.and Blakemore, R.P., J. Bacteriol., 1988, 170, 834.

6. Bazylinski, D.A., ASM News, 1995, 61, 337.

7. Bazylinski, D.A., Garratt-Reed, A.J. and Frankel, R.B., Microsc. Res. Tech., 1994, 27, 389.

8. Hanzlik, M.M., Winklhofer, M. and Petersen, N., Earth Planet. Sci. Lett., 1996, 145, 125. 
9. Frankel, R.B., Blakemore, R.P. and Wolfe, R.S., Science, 1979, 203, 1355.

10. Mann, S., Sparks, N.H.C., Frankel, R.B., Bazylinski, D.A. and Jannasch, H.W. Nature, 1990, 343, 258.

11. Farina, M., Motta de Esquivel, D. and Lins de Barros, H.G.P., Nature, 1990, 343, 256.

12. Bazylinski, D.A. and Frankel, R.B., in Biomineralization Processes of Iron and

Manganese: Modern and Ancient Environments, eds. H.C.W. Skinner and R.W. Fitzpatrick, Catena, 1992, 147.

13. Blakemore, R.P., Annu. Rev. Microbiol., 1982, 36, 217.

14. Mann, S., Frankel, R.B. and Blakemore, R.P., Nature, 1984, 310, 405.

15.Towe, K.M. and Moench, T.T., Earth Planet. Sci. Lett., 1981, 52, 213.

16. Bazylinski, D.A., Frankel, R.B. and Jannasch, H.W., Nature, 1988, 334, 518.

17. Mann, S., Sparks, N.H.C. and Blakemore, R.P., Proc. R. Soc. London B, 1987, 231, 469.

18. Mann, S., Sparks, N.H.C. and Blakemore, R.P., Proc R Soc London B, 1987, 231, 477.

19. Thornhill, R.H., Burgess, J.G., Sakaguchi, T. and Matsunaga, T., FEMS Microbiol Lett., 1994, 115, 169.

20. Vali H. and Kirschvink, J.L., in Iron Biominerals, eds. R.B. Frankel and R.P. Blakemore, Plenum Press, 1990, 97.

21. Matsuda, T., Endo, J., Osakabe, N., Tonomura, A. and Arii, T., Nature, 1983, 302, 411.

22. Mann, S., Moench, T.T. and Williams, R.J.P., Proc. R. Soc. London B, 1984, 221, 385.

23. Meldrum, F.C., Heywood, B.R., Mann, S., Frankel, R.B. and Bazylinski, D.A., Proc. R. Soc. London B, 1993, 251, 231.

24. Meldrum, F.C., Heywood, B.R., Mann, S., Frankel, R.B. and Bazylinski, D.A., Proc. R. Soc. London B, 1993, 251, 237.24.

25. Mann, S. and Frankel R.B., in Biomineralization: Chemical and Biochemical

Perspectives, eds. S. Mann, J. Webb and R.J.P. Williams, VCH Publishers, 1989, 389.

26. Frankel, R.B.and Bazylinski, D.A., Hyperfine Interactions, 1994, 90, 135.

27. Lovley, D.R., Microbiol. Rev., 1991, 55, 259.

28. Heywood, B.R., Bazylinski, D.A., Garratt-Reed, A.J., Mann, S. and Frankel, R.B., Naturwiss., 1990, 77, 536.

29. Heywood, B.R., Mann, S. and Frankel, R.B., in Materials Synthesis Based on Biological Processes, eds. M. Alpert, P. Calvert, R.B. Frankel, P. Rieke and D. Tirrell, Materials Research Society, 1991, 93.

30. Chang, S-B.R. and Kirschvink, J.L., Annu. Rev. Earth. Planet. Sci., 1989, 17, 169.

31. Farina, M., Kachar, B., Lins, U., Broderick, R. and Lins de Barros H., J. Microsc., 1994, $173,1$.

32. Dunlop, D.J. and Özdemir, Ö., Rock Magnetism: Fundamentals and Frontiers, Cambridge University Press, 1997.

33. Frankel, R.B., Annu. Rev. Biophys. Bioeng., 1984, 13, 85. 
34. Penninga, I., deWaard, H., Moskowitz, B.M., Bazylinski, D.A. and Frankel, R.B., J. Magn. Magn. Mater., 1995, 149, 279.

35. Moskowitz, B.M., Rev. Geophys. Supp., 1995, 123.

36. Donaghay, P.L., Rines, H.M. and Sieburth, J.M., Arch. Hydrobiol. Beih. Ergebn. Limnol., 1992, 36, 97.

37. Wakeham, S.G., Howes, B.L., Dacey, J.W.H., Schwarzenbach, R.P. and Zeyer, J., Geochim.Cosmochim. Acta, 1987, 51, 1675.

38. Bazylinski, D.A., Frankel, R.B., Heywood, B.R., Mann, S., King, J.W., Donaghay, P.L. and Hanson, A.K., Appl Environ Microbiol, 1995, 61, 3232.

39. DeLong, E.F., Frankel, R.B. and Bazylinski, D.A., Science, 1993, 259, 803.

40. Frankel, R.B., Bazylinski, D.A., Johnson, M. and Taylor, B.L., Biophys. J., 1997, 73, 994.

41. Kimble, L.K.and Bazylinski, D.A. Abstr 96th Annu Meet Am Soc Microbiol ., K-174, 1996.

42. Maratea, D. and Blakemore, R.P., Int'l. J. Syst .Bacteriol., 1981, 31, 452.

43. Schleifer, K-H., Schüler, D., Spring, S., Weizenegger, M., Amann, R., Ludwig, W. and Kohler, M., Syst. Appl. Microbiol., 1991, 14, 379.

44. Matsunaga, T., Sakaguchi, T. and Tadokoro, F., Appl. Microbiol. Biotechnol., 1991, 35, 651 .

45. Sakaguchi, T., Burgess, J.G. and Matsunaga, T., Nature, 1993, 365, 47.

46. Neilands, J.B., Biol. Metals, 1984, 4, 1.

47. Guerinot, M.L., Annu. Rev. Microbiol., 1994, 48, 743.

48. Paoletti, L.C. and Blakemore, R.P., J. Bacteriol., 1986, 167, 73.

49. Frankel, R.B., Papaefthymiou, G.C., Blakemore, R.P. and O'Brien, W., Biochim.

Biophys. Acta, 1983, 763, 147.

50. Nakamura, C., Sakaguchi, T., Kudo, S., Burgess, J.G., Sode, K.and Matsunaga, T., Appl. Biochem. Biotechnol., 1993, 39/40, 169.

51. Schüler, D. and Baeuerlein, E., Arch. Microbiol., 1996, 166, 301.

52. Baeuerlein, E. and Schüler, D., J. Inorg. Biochem., 1995, 59, 107.

53. Tamegai, H., Yamanaka, T. and Fukumori, Y., Biochim. Biophys. Acta, 1993, 1158, 237.

54. O’Brien, W., Paoletti, L.C. and Blakemore, R.P., Curr. Microbiol., 1987, 15, 121.

55. Tamegai, H. and Fukumori, Y., FEBS Lett., 1994, 347, 22.

56. Yamazaki, T., Oyanagi, H., Fujiwara, T. and Fukumori, Y., Eur. J. Biochem., 1995, 233, 665.

57. Waleh, N.S., Mol. Gen. Genet., 1988, 214, 592.

58. Berson, A.E., Peters, M.R.and Waleh, N.S., Arch. Microbiol., 1989, 152, 567.

59. Berson, A.E., Peters, M.R.and Waleh, N.S., Nucl. Acids. Res., 1990, 18, 675

60. Berson, A.E., Hudson, D.V.and Waleh, N.S., Mol. Microbiol., 1991, 5, 2261. 
61. Matsunaga, T., Nakamura, C., Burgess, J.G. and Sode, K., J. Bacteriol., 1992, 174, 2748.

62. Nakamura, C., Burgess, J.G., Sode, K.and Matsunaga, T., J. Biol. Chem., 1995, 270, 28392.

63. Okuda, Y., Denda, K.and Fukumori, Y., Gene, 1996, 171, 99.

64. Bazylinski, D.A., Heywood, B.R., Mann S.and Frankel R.B., Nature, 1993, 366, 218.

65. Silverman, M. and Simon, M., Nature, 1974, 249, 73.

66 Spormann, A.M. and Wolfe, R.S., FEMS Microbiol. Lett., 1984, 22, 171.

67. Blakemore, R.P., Maratea, D.and Wolfe, R.S., J. Bacteriol., 1979, 140, 720.

68. Zhulin, I.B., Bespalov, V.A., Johnson, M.S. and Taylor, B.L., J. Bacteriol., 1996, 178, 5199.

69. Segall, J.E., Block, S.M. and Berg, H.C., Proc. Natl. Acad. Sci. USA, 1986, 83, 8987.

70. Taylor, B.L., Trends Biochem. Sci., 1983, 8, 438.

71. Manson, M.D., Adv. Microbial Physiol., 1992, 33, 277.

72. Blakemore, R.P., Frankel, R.B.and Kalmijn, A.J., Nature, 1980, 236, 384.

73. McKay, D.S., Gibson, E.K.,Jr., Thomas-Keprta, K.L., Vali, H., Romanek, C.S., Clemett, S.J., Chillier, X.D.F., Maechling, C.R.and Zare, R.N. Science, 1996, $273,924$.

74. Bradley, J.P., Harvey, R.P.and McSween, H.Y.,Jr., Geochim. Cosmochim. Acta, 1996, 60, 5149 . 


\section{FIGURE CAPTIONS}

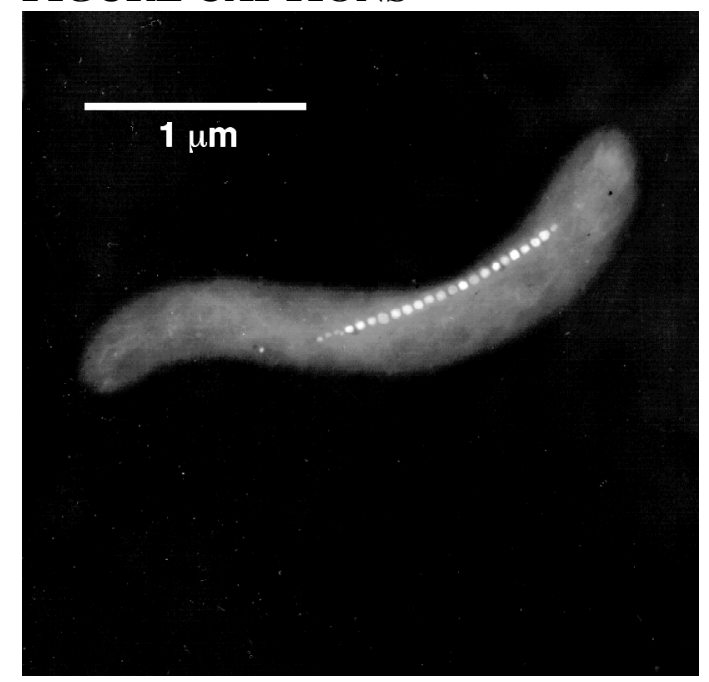

Figure 1. Negative TEM image of $M$ magnetotacticum, strain MS-1, showing the chain of magnetosomes that constitutes a permanent magnetic dipole in the cell. The magnetosomes contain ca. $42 \mathrm{~nm}$ particles of magnetite, $\mathrm{Fe}_{3} \mathrm{O}_{4}$. The particles are cubo-octahedra with [111] axes oriented along the chain direction ${ }^{14}$. The single polar flagellum at each end of the cell that is responsible for motility is not visible. 


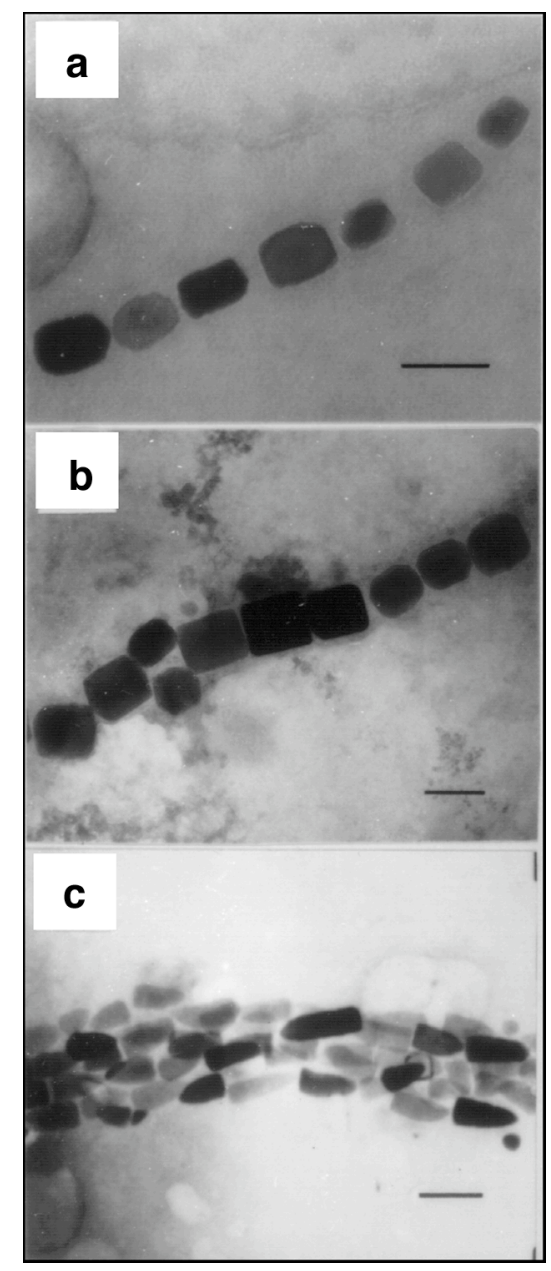

Figure 2. TEM images of magnetosomes in several magnetotactic bacterial strains: a) parallelepiped form in a marine vibrio, strain MV-1; b) parallelepiped form in a marine coccus, strain MC-1; c) tooth-shaped form in an unidentified marine rod. The bars in each panel represent $100 \mathrm{~nm}$. 


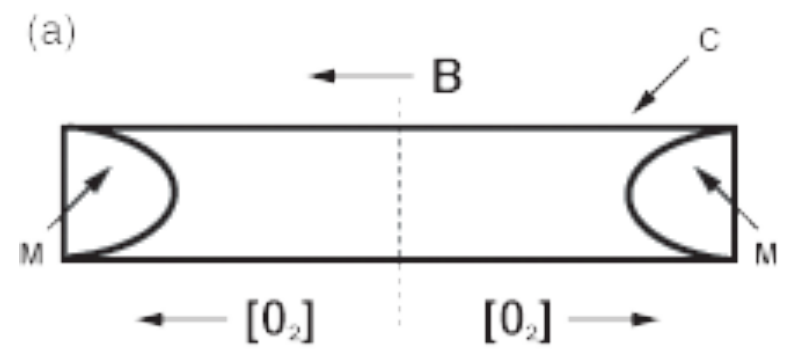

(b)

Axial Magneto-Aerotaxis

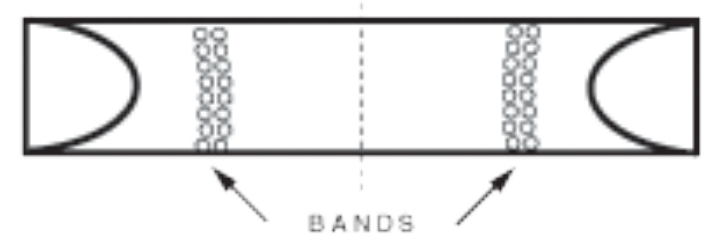

(c)

Polar Magneto-Aerotaxis

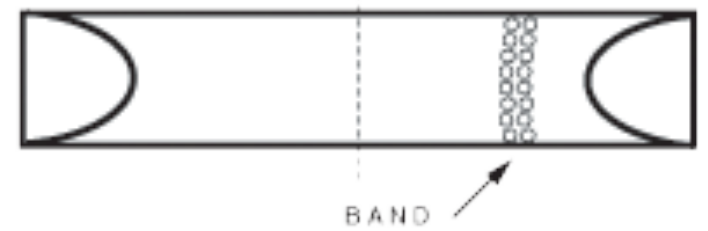

Figure 3. a) Schematic drawing of the thin, flat capillary (c) (VitroCom, Mountain Lakes, NJ; cross section $0.2 \mathrm{~mm} \times 5 \mathrm{~mm}$ ) used to distinguish polar and axial magneto-aerotaxis. The tube was filled with bacteria in reduced medium, resulting in a meniscus (m) at both ends.

Diffusion of oxygen into the medium resulted in an increase of the oxygen concentration $\left[\mathrm{O}_{2}\right]$ from the center of the tube towards the ends. The tube was place in an static magnetic field (B) of the order of a few gauss, oriented along the tube. b) Band formation by axial magneto-aerotactic cells, such as M. magnetotacticum, strain MS-1, occurred at both ends of the capillary. Rotation of the magnetic field by $180^{\circ}$ after the bands formed caused the cells in the bands at either end of the capillary to rotate $180^{\circ}$, but the bands remained intact. c) Band formation by polar magneto-aerotactic cells, such as the marine coccus, strain MC-1, occurred only at the end of the capillary for which the magnetic field and the oxygen concentration gradient were oriented opposite to each other. Rotation of the magnetic field by $180^{\circ}$ after the band formed caused the cells in the band to rotate $180^{\circ}$ and swim away from the band, resulting in dispersal of the band. 